\title{
Effectiveness of aripiprazole once-monthly in schizophrenia patients pretreated with oral aripiprazole: a 6-month, real-life non-interventional study
}

\author{
Daniel Schöttle ${ }^{1 *} \mathbb{B}$, Wolfgang Janetzky ${ }^{2}$, Daniel Luedecke ${ }^{1}$, Elmar Beck ${ }^{3}$, Christoph U. Correll ${ }^{4,5,6}$
} and Klaus Wiedemann ${ }^{1}$

\begin{abstract}
Background: In this study, the treatment of schizophrenia patients with aripiprazole once-monthly (AOM) was evaluated under real-life conditions in a naturalistic setting.

Methods: This multicenter, prospective, non-interventional study included 242 patients (age $=43.1 \pm 15.1$ years, $55.0 \%$ male) who were monitored during 6 months of AOM treatment. Endpoints included measurements of psychopathology (Brief Psychiatric Rating Scale, BPRS) and severity of illness scales (Clinical Global ImpressionsSeverity, CGI-S, and -Improvement, CGI-I). Furthermore, treatment-related adverse events (TRAEs) were recorded.

Results: At baseline, the mean BPRS total score was $54.1 \pm 15.6$, the mean CGI-S was $4.8 \pm 0.8$ and the most frequent illness category was 'markedly ill' (41.7\%). Patients had been pretreated with oral aripiprazole for a mean duration of 9.7 months (SD: 22.3) and $87.9 \%$ were deemed by their clinician as "clinically stable" and for a mean of 5.9 months. The difference in global BPRS after 6 months was -13.8 (SD: 16.0; 95\% Cl: $[-15.9 ;-11.7] ; p<0.001$ ). The proportion of patients with high CGI-S scores decreased and the proportion of patients with low scores increased significantly ( $p<0.001$, respectively). BPRS scores improved numerically especially well in younger patients $\leq 35$ years, CGI-S scores decreased significantly more in this population. TRAEs were rare, with low incidences of extrapyramidal symptoms (2.9\%) or weight increase $(0.4 \%)$.

Conclusions: Treatment with AOM showed satisfying effectiveness in outpatients with further improvement of psychopathology after oral aripiprazole treatment for a considerable duration and even after having achieved clinically judged "stability". Our findings indicate a robust therapeutic effect of AOM and substantiate previous results from randomized controlled trials under real-world routine conditions.
\end{abstract}

Keywords: Long-acting injectable, LAl, Naturalistic, Schizophrenia, Schizoaffective

\section{Background}

Schizophrenia is one of the most complex psychiatric disorders often leading to considerable disability and affecting the lives of patients and their families profoundly $[1,2]$. Non- or partial adherence to psychopharmacological therapy is one of the major risk factors for relapses $[3,4]$,

\footnotetext{
* Correspondence: d.schoettle@uke.de

${ }^{1}$ Klinik für Psychiatrie und Psychotherapie, Zentrum für Psychosoziale

Medizin, Universitätsklinikum Hamburg-Eppendorf, Martinistrasse 52, 20246

Hamburg, Germany

Full list of author information is available at the end of the article
}

which severely diminish the psychosocial and occupational functioning of patients and negatively affect their quality of life $[3,5,6]$. Treatment with antipsychotics, as a major component in a framework of social and psychological therapies, can help to overcome these impairments and is highly effective [2]. However, nonadherence to treatment in patients with schizophrenia is frequently observed $[4,7,8]$ with a significantly heightened risk of subsequent relapses [9]. Even small gaps in taking medication can have a significant effect, as stopping medication for as little as one to 10 days in a one-year period (partial adherence) was found to

(c) The Author(s). 2018 Open Access This article is distributed under the terms of the Creative Commons Attribution 4.0 International License (http://creativecommons.org/licenses/by/4.0/), which permits unrestricted use, distribution, and 
be associated with a significantly increased risk of hospitalization, with an odds ratio of 1.98 [10], while intermittent use of medication leads to a 3-fold higher risk of relapse in stable patients [11]. Improving adherence to medication may be achieved by using long-acting injectable antipsychotics (LAIs) which may in turn reduce the risk of relapse and improve patient functioning [12-14].

Aripiprazole once-monthly (AOM) is an atypical LAI with a unique pharmacological profile: aripiprazole shows partial agonist activity at dopamine D2/D3 receptors $[15,16]$, therefore the risk of adverse effects, such as parkinsonism, hyperprolactinemia and sexual dysfunction [17] is low. Effects on serotonin receptors include a partial agonist activity at the $5-\mathrm{HT}_{1 \mathrm{~A}}$ receptor [18] and antagonist activity at $5-\mathrm{HT}_{2 \mathrm{~A}}$ receptor [19], which adds to the antipsychotic profile. The efficacy and tolerability of AOM in patients with schizophrenia has been demonstrated by two randomized, double-blind, controlled studies (RCTs) conducted in the United States [20] and Europe [21]. In the study by Kane et al., $10 \%$ of patients in the active group and $39.6 \%$ in the placebo group experienced exacerbation of psychotic symptoms or impending relapse (hazard ratio $=5.03$ ) at study endpoint. Altogether, $2.6 \%$ vs. $3.7 \%$ of patients were hospitalized because of relapse. In the European study, KaplanMeier estimated impending relapse rates at week 26 from randomization were $7.1 \%$ for AOM $400 \mathrm{mg}, 7.8 \%$ for oral aripiprazole $(10-30 \mathrm{mg} /$ day $)$ and $21.8 \%$ for aripiprazole once-monthly at a subtherapeutic dose $(50 \mathrm{mg})$ [21]. AOM $400 \mathrm{mg}$ has a long half-life of 46.5 days [22], which potentially can provide long-term relapse protection for patients.

In the present non-interventional study, the course of schizophrenia was monitored in patients receiving AOM treatment under usual care conditions. The primary endpoint was the assessment of AOM effectiveness on psychopathology by the attending psychiatrist, using the Brief Psychiatric Rating Scale (BPRS). Secondary endpoints included measurement of illness severity and illness improvement using the Clinical Global Impressions- Severity (CGI-S) and - Improvement (CGI-I) scales and the documentation of treatment related adverse events (TRAE). In addition, other instruments measuring functional status and wellbeing of the patients were applied such as the Global Assessment of Functioning (GAF), the WHO-5 scale, and medical resources used, which are part of a separate manuscript. The data collected in this study in a heterogeneous patient sample were intended to confirm the results of the previous efficacy studies [20, 21], which were conducted in a homogenous population of patients and which were intended for regulatory approval of AOM. Thus, we hypothesized that 6 months of AOM treatment would significantly improve psychopathology in patients receiving usual-care based AOM treatment.

\section{Methods}

Design

This multicenter, prospective, non-interventional study was designed according to the German Medicinal Products Act and approved by the Freiburg ethics commission international (Approval number: 014/1336). Diagnosis, treatment and monitoring of patients were conducted in a naturalistic, usual care treatment setting. Prospective collection of the data was chosen to collect high quality data, and a multicenter approach was chosen to ensure an adequate sample size. Patients were only recruited for the study after the treating psychiatrist had chosen AOM treatment for these patients based on clinical grounds. Since this was a naturalistic sample, combinations with other psychiatric medications, including oral antipsychotics were based on clinician's choice. Participation in the study had no influence on treatment choice.

Seventy-five centers participating in this study were located throughout Germany. The observation period for each patient was about 6 months. Data were collected from July 2014 to March 2016, when the last patient of the target sample had reached 6 months. Data were collected at seven time points (T0-T6), each about 4 weeks apart $(-2 /+5$ days). BPRS data were collected at T0, T3 (month 3) and T6 (month 6), and data for all other endpoints were collected at each monthly time point (except CGI-I, no baseline assessment possible; Fig. 1).

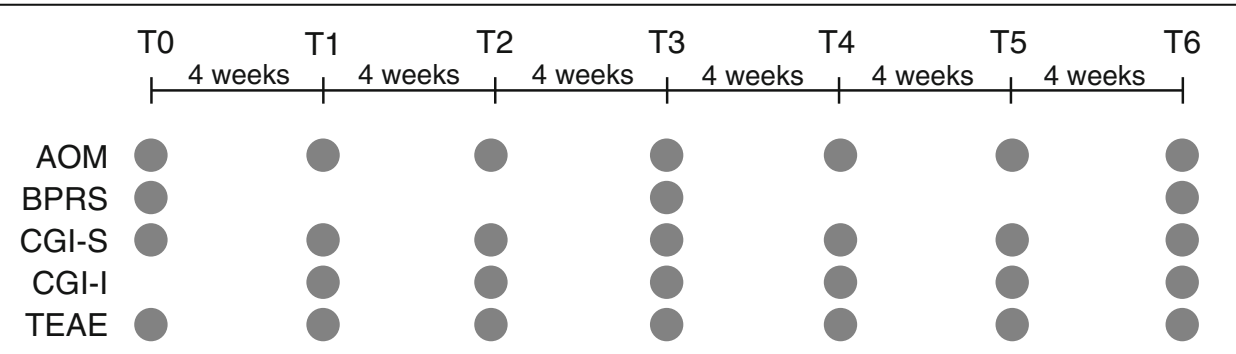

Fig. 1 Study design. Patients were treated with AOM at seven time points (TO-T6) that were each 4 weeks apart. Data for the different endpoints were collected at the indicated time points. AOM, Aripiprazole once-monthly; BPRS, Brief Psychiatric Rating Scale; CGI-S, Clinical Global Impression Severity; CGI-I, Clinical Global Impression - Improvement; TRAE, treatment related adverse events 


\section{Patients}

Patients in the study cohort were $\geq 18$ years old and diagnosed with schizophrenia (F20.X) according to ICD-10. Starting from the time of inclusion in the study, patients were treated with AOM on an outpatient basis according to prescribing information and clinical need. The treatment choice was independent from the study. All patients gave written informed consent.

Exclusion criteria for the study were contraindications for AOM, being a member or being related to a member of the study staff, pregnancy, planning a pregnancy, breastfeeding, or expected reluctance to follow the prespecified monitoring plan (as assessed by the treating psychiatrist).

\section{Assessments}

The BPRS is a clinician-rated scale [23] which is well established in clinical routine, and therefore it was used as the primary endpoint in this study. Eighteen items were assessed that are grouped into 5 domains: anxiety/ depression, anergia, thought disorders, activation and hostility/mistrust. Each of the respective items was rated on a seven-point scale ranging from 1 (not present) to 7 (extremely severe).

The Clinical Global Impression - Severity scale (CGI-S) was used to report the current severity of the patient's mental illness on a seven-point scale ranging from 1 (normal, not at all ill) to 7 (extremely ill) [24]. This rating was complemented by the CGI-I (Improvement) scale, in which improvement of the mental illness from the beginning of the study is rated on a seven-point scale (1, very much improved to 7, very much worse).

Any patient reported adverse events were documented during the study and rated by the clinicians as treatment related adverse events (TRAE) or unrelated to treatment. Patients were asked about adverse events, comorbidities and comedications at every visit. Adverse events were coded according to MedDRA 19.0.

Other rating scales used in the same study will be discussed elsewhere.

\section{Statistical analysis}

The primary outcome, change in BPRS total score from baseline to endpoint was analyzed using the Wilcoxon Signed-Rank test for paired samples, and the Wilcoxon's rank-sum test for independent samples. Changes in marginal distributions in contingency tables of categorical outcomes were analyzed using Bhapkar's test and proportions within one group of patients with the binomial test. Fisher's exact test was used to compare proportions between groups of patients. Missing values were imputed using the Last Observation Carried Forward (LOCF) method if there was a value for T0 and at least one post-baseline time point. There was one prespecified subgroup analysis for the primary outcome, i.e., the comparison of patients aged $\leq 35$ years old vs patients aged $>35$ years old, as the younger age group had performed significantly better than the older age group in a prior AOM efficacy study [25]. Subgroup comparisons by age group were covaried using a linear regression analysis with backward selection of effects for variables that differed significantly between the two age groups at baseline at $p<0.05$ (see Table 1). All data were processed using SAS $^{\text {тм }}$ software (SAS Institute, Cary, NC/USA), with all tests being two-sided and alpha $=0.05$, without correction for multiple testing for secondary outcomes.

\section{Results}

\section{Baseline assessments}

Two hundred seventy eight patients were reported by the treating clinicians to be eligible for the study. After screening, 243 patients were included in the study. Patient baseline demographics are presented in Table 1. Altogether, 204 patients (84.3\%) completed all scheduled visits, and 23 patients (9.5\%) came for at least the first and last visits.

Diagnoses included paranoid schizophrenia (ICD-10: F20.0) in 202 patients (83.5\%), non-differentiated schizophrenia in 22 patients (9.1\%; ICD-10: F20.3) and others for the remaining 18 patients (7.4\%). All patients had been previously treated with oral aripiprazole for a mean duration of 9.7 months (SD 22.3 months), with $33.3 \%$ of patients having received oral aripiprazole for $<1$ month, $39.9 \%$ for $1-6$ months, and $26.8 \%$ for more $>6$ months. Apart from aripiprazole treatment, 141 patients (58.3\%) had been treated with additional medication, and the most common substances were risperidone, quetiapine, and olanzapine $(35,34$ and 28 patients, respectively, being $14.5 \%, 14,1$, and $11.6 \%$ of the patient population).

At study start, 20 patients $(8.5 \%)$ received $5 \mathrm{mg}$ oral aripiprazole, $183(77.5 \%)$ received $10-20 \mathrm{mg}$, and 33 (14.0\%) received a higher oral aripiprazole dose. During oral aripiprazole treatment, most patients had been symptomatically stable, as assessed by the treating psychiatrist (without use of a dedicated rating scale), for a mean duration of 5.9 months (standard deviation 18.2), with 91 patients (39.2\%) being stable for $<1$ month and $28(12.1 \%)$ being not stable at all. At the start of the study 81 patients (33.5\%) received further medication apart from aripiprazole (Table 2).

Reasons for the decision to switch from treatment with oral aripiprazole to AOM were most often (48.4\%) easier adherence to treatment, followed by good/better tolerability $(16.9 \%)$, patient's request $(13.6 \%)$, good/better efficacy $(12.0 \%)$ and easier use $(9.1 \%)$ than oral treatment. Switching was a subjective decision of treating clinicians to further improve outcome in a naturalistic sample of patients. At study start, $79.3 \%$ of patients received $400 \mathrm{mg}$ of injectable aripiprazole, $17.4 \%$ received 
Table 1 Patient baseline demographics

\begin{tabular}{|c|c|c|c|c|}
\hline Characteristic & $\begin{array}{l}\text { Total } \\
(n=242)\end{array}$ & $\begin{array}{l}\text { Patients aged } \leq 35 \text { years } \\
(n=89)\end{array}$ & $\begin{array}{l}\text { Patients aged }>35 \text { years } \\
(n=153)\end{array}$ & $P$-value \\
\hline Age, mean (SD), years & $43.1(15.1)$ & $28.8(4.3)$ & $51.3(12.7)$ & $<0.0001^{2}$ \\
\hline Sex, male, n (\%) & $133(55.0)$ & $57(64.0)$ & $76(49.7)$ & $0.0328^{\mathrm{b}}$ \\
\hline Family status, n (\%) & & & & $<.0001^{\mathrm{b}}$ \\
\hline Single & $151(62.7)$ & $74(84.1)$ & $77(50.3)$ & \\
\hline Married/in a relationship & $53(22.0)$ & $13(14.8)$ & $40(26.1)$ & \\
\hline Divorced & $23(9.5)$ & $1(1.1)$ & $25(16.3)$ & \\
\hline Widowed & $11(4.6)$ & $0(0.0)$ & $11(7.2)$ & \\
\hline Employment status, n (\%) & & & & $<.0001^{\mathrm{b}}$ \\
\hline Employed & $43(18.0)$ & $23(26.4)$ & $20(13.2)$ & \\
\hline Unemployed & $73(30.5)$ & $36(41.4)$ & $37(24.3)$ & \\
\hline Annuitant & $99(41.4)$ & $13(14.9)$ & $86(56.6)$ & \\
\hline Housewife/househusband & $11(4.6)$ & $2(2.3)$ & $9(5.9)$ & \\
\hline In school/education/re-education & $13(5.4)$ & $13(15.0)$ & $0(0.0)$ & \\
\hline Duration of untreated psychosis, mean (SD), years & $1.2(8.0)$ & $1.4(3.2)$ & $1.0(9.8)$ & $0.7719^{\mathrm{a}}$ \\
\hline Age at diagnosis, mean (SD), years & $30.9(13.0)$ & $23.0(4.3)$ & $35.3(14.2)$ & $<.0001^{\mathrm{a}}$ \\
\hline Time of diagnosis, n (\%) & & & & $<.0001^{\mathrm{b}}$ \\
\hline Within the last 5 years & $78(32.4)$ & $47(53.4)$ & $31(20.3)$ & \\
\hline More than 5 years ago & $163(67.6)$ & $41(46.6)$ & $122(79.7)$ & \\
\hline No. of illness episodes, n (\%) & & & & $0.0002^{\mathrm{b}}$ \\
\hline First episode of schizophrenia & $19(7.9)$ & & & \\
\hline$\leq 5$ episodes & $137(57.1)$ & $64(72.7)$ & $73(48.0)$ & \\
\hline$>5$ episodes & $103(42.9)$ & $24(27.3)$ & $79(52.0)$ & \\
\hline $\mathrm{BMI}$, mean $(\mathrm{SD}), \mathrm{kg} / \mathrm{m}^{2}$ & $29.3(6.9)$ & $28.6(7.3)$ & $29.7(6.6)$ & $0.2381^{\mathrm{a}}$ \\
\hline Underweight (<18,5), n (\%) & $3(1.3)$ & $3(3.5)$ & $0(0.0)$ & \\
\hline Normal weight $(18,5<25)$, n (\%) & $59(24.6)$ & $21(24.1)$ & $38(24.8)$ & \\
\hline Overweight $(25<30)$, n (\%) & 95 (39.6) & $36(41.4)$ & 59 (38.6) & \\
\hline Obese ( $\geq 30), n(\%)$ & $83(34.6)$ & $27(31.0)$ & $56(36.6)$ & \\
\hline BPRS at baseline, mean (SD) & $54.1(15.6)^{c}$ & $53.0(16.1)^{d}$ & $53.7(15.9)^{d}$ & $0.7608^{\mathrm{a}}$ \\
\hline CGI-S at baseline, mean (SD) & $4.8(0.8)$ & $4.7(0.9)$ & $4.8(0.8)$ & \\
\hline CGI-S at baseline, n (\%) & & & & $0.7081^{b}$ \\
\hline Mildly ill & $12(5.0)$ & $6(6.8)$ & $6(4.0)$ & \\
\hline Moderately ill & 79 (32.9) & $30(34.1)$ & $49(32.2)$ & \\
\hline Markedly ill & $100(41.7)$ & $33(37.5)$ & $67(44.1)$ & \\
\hline Severely ill & $48(20.0)$ & $19(21.6)$ & $29(19.1)$ & \\
\hline Extremely ill & $1(0.4)$ & $0(0.0)$ & $1(0.7)$ & \\
\hline
\end{tabular}

In cases where percentages do not add up to 100, data were missing for some patients

$B M I$ body mass index, BPRS Brief Psychiatric Rating Scale, CGI-S Clinical Global Impressions-Severity Scale, SD standard deviation

$a_{\text {t-Test }}$

bisher's exact Test

cfull analysis set (last observation carried forward)

dall values

$300 \mathrm{mg}, 2.9 \%$ received $200 \mathrm{mg}$ and one patient $(0.4 \%)$ received $160 \mathrm{mg}$. Most patients (132, 54.6\%) were treated with $400 \mathrm{mg}$ of injectable aripiprazole at every time point $\mathrm{T} 0-\mathrm{T} 6$, and 12 patients $(5.0 \%)$ received $300 \mathrm{mg}$ at all time points. Of the remaining patients, $30.6 \%$ were treated with different AOM doses, and 9.9\% discontinued treatment. Reasons for discontinuation of AOM included patient's request $(9,3.7 \%)$, lack of effectiveness (7, 2.9\%), adverse drug reactions $(6,2.5 \%)$, and patients not arriving at agreed appointments, having moved to a 
Table 2 Comorbidities and comedications

\begin{tabular}{lc}
\hline Frequent comorbidities, $\mathrm{n}(\%)$ & $24(9.9)$ \\
Hypertension & $20(8.3)$ \\
Depression & $16(6.6)$ \\
Diabetes mellitus & $13(5.4)$ \\
Obesity & $7(2.9)$ \\
Hyperthyroidism & $5(2.1)$ \\
Anxiety & $13(5.4)$ \\
Frequent comedications for treatment of somatic diseases, n (\%) \\
Metformin & $12(5.0)$ \\
Bisoprolol & $10(4.1)$ \\
Ramipril & $15(6.2)$ \\
Frequent comedications for treatment of mental diseases, n (\%) \\
Venlafaxine & $6(2.5)$ \\
Duloxetine & $5(2.1)$ \\
Mirtazapine & $70(28.9)$ \\
Benzodiazepines & $12(5.0)$ \\
Additional drugs to treat schizophrenia at the start of the study, n (\%) \\
Quetiapine \\
Olanzapine \\
Clozapine
\end{tabular}

new house, or undergoing inpatient drug addiction therapy (1 case each, $0.4 \%$ each; one patient gave two reasons for discontinuation). AOM adherence was monitored based on injection visits taking place, yielding that $84 \%$ of the patients were fully adherent, $8 \%$ were adherent to receiving $>70 \%$ of injections, and that $8 \%$ had lower adherence rates. After the 6-month observational period, 200 patients (89.3\%) decided to continue AOM treatment.

At baseline, the CGI-S category with the most patients (41.7\%) was "markedly ill". The mean global BPRS value was 54.1 ( \pm 15.6 , standard deviation, SD) (Fig. 2), and $94.5 \%$ presented with a GCI-S value of $\geq 4$ (moderately severe) (Fig. 5).

\section{Brief psychiatric rating scale (BPRS)}

The psychopathological status of the patients improved significantly during treatment, as assessed via the BPRS $(p<0.0001$, Fig. 2). One hundred eighty-seven patients $(82.0 \%)$ improved during the study, 12 (5.3\%) remained the same, and 29 (12.7\%) had worse global BPRS scores at T6, seven of which worsened by more than 10 points. Altogether, 131 patients $(57.5 \%)$ had a reduction of their global BPRS value by at least $20 \%$. In total, the difference in global BPRS between T6 and T0 was - 13.8 (SD: 16.0; 95\% CI: [-15.9; -11.7$] ; p<0.001)$. The largest improvements were found in the scores anxiety/depression (T6-T0: -0.98; SD: 1.21; 95\% CI: [- 1.14; - 0.83]) and activation (T6-T0: -0.82; SD: 1.15; 95\% CI: [- 0.97; - 0.67]) (Fig. 3; score reduction must be multiplied by number of respective items to obtain total score reduction).

For patients $\leq 35$ years, the difference between global BPRS values at T6 and T0 was -17.2 (SD: 17.6; 95\% CI: $[-21.1 ;-13.4])$. For patients $>35$ years, the difference was - 11.9 (SD: 14.6; 95\% CI: [- 14.3; - 9.5]) (Fig. 4). This difference was not significant $(p=0.0746$, Wilcoxon two-sample test). The differences in subscores are presented in Table 3.

\section{Clinical global impression (CGI)}

Severity of illness as the secondary study outcome was measured using the CGI-S score. During the study, the proportion of patients with high scores became smaller, while the proportion with low scores increased (Fig. 5). At baseline, 146 patients $(62.1 \%)$ had a severity score of 5 (markedly ill) or worse. At T6, only 75 (31.9\%) remained with a score of 5 or 6 . By contrast, at baseline only 12 patients (5.1\%) scored as "mildly ill" (3), whereas at T6, 87 patients $(37.0 \%)$ had a score of 3 or better. These improvements were found to be highly significant $(p<0.001)$ using Bhapkar's test.

According to the CGI-S scores, 222 patients (94.5\%) were stable (scores improved or remained the same) during the study. Altogether, 57 patients (24.3\%) improved by

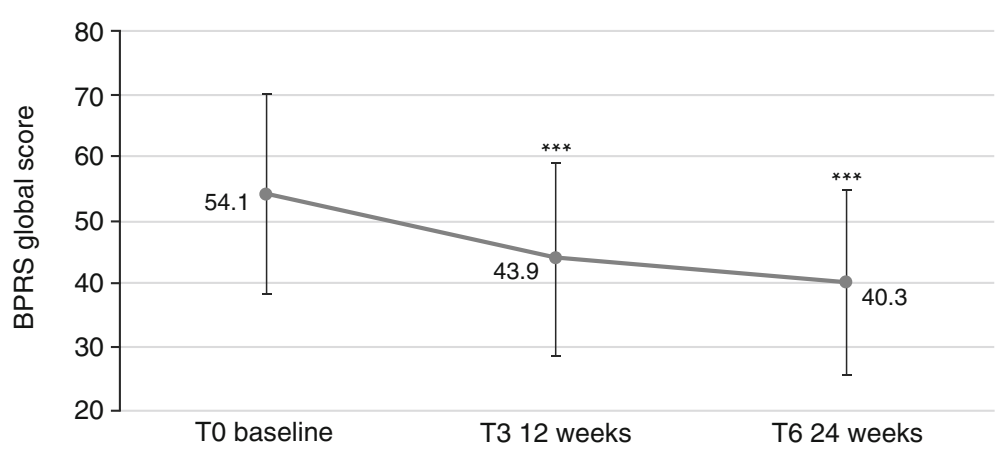

Fig. 2 Effects of AOM treatment on Brief Psychiatric Rating Scale (BPRS), global score (sum of values for all items). 18: symptoms not present, 126: symptoms extremely severe. ${ }^{* * *} p<0.001$. Error bars represent standard deviations 


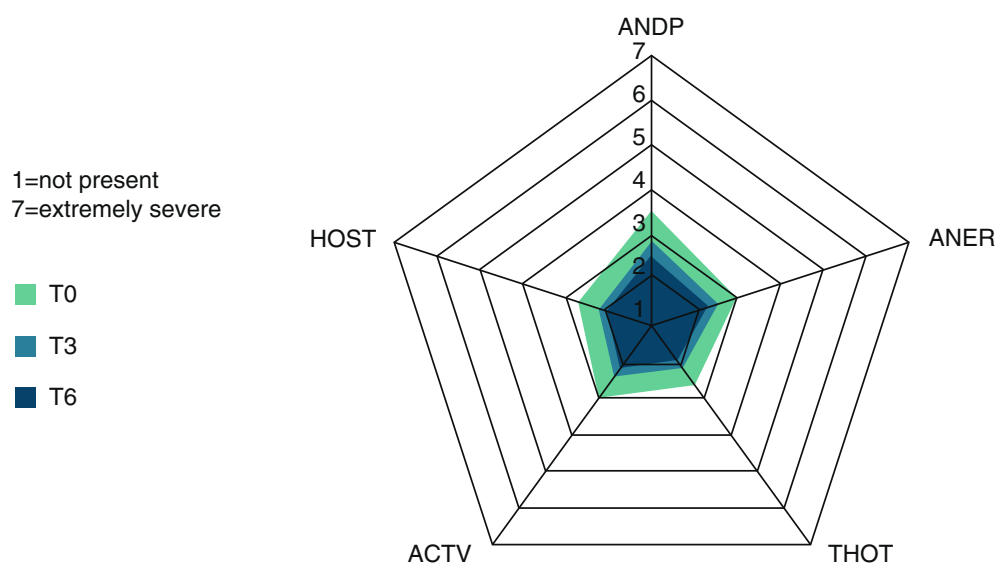

Fig. 3 Profile for each score at baseline (T0), follow-up visit (T3) and last visit (T6) assessed by BPRS. ANDP: anxiety/depression; ANER: anergia; THOT: thought disorders; ACTV: activation; HOST: hostility/mistrust

two points or more (Fig. 6). Thirteen patients (5.4\%) deteriorated, with a mean score of 1.3 points on the scale (four patients deteriorated by two points, another nine patients by one point each).

These improvements were also reflected by CGI-I scores: At T6, 35 (15.2\%) of patients were rated as very much improved (score of 1) compared to baseline, and $96(42.0 \%)$ were rated as much improved (score of 2 ).

In patients $>35$ years, $18.8 \%(n=28)$ improved by 2 points or more on the CGI-S scale, whereas in younger patients ( $\leq 35$ years), this was true for $33.7 \%(n=29)$ of patients. Only $8.8 \%(n=13)$ of older patients had a CGI-I score of 1 (very much improved) at T6, whereas in younger patients, this was the case for $26.2 \%(n=22)$. The difference between age groups regarding CGI-I scores at T6 was significant ( $p=0.0074$, Fisher's exact test).

\section{Adverse events}

During the study, a total of 153 adverse events (AE) were reported by patients (Table 4 ) and coded according to MedDRA 19.0. One hundred thirty-three of these AEs were rated by the clinician as probably or possibly treatment-related (TRAE). Only one type of event, "medication taken at an inappropriate time", applied to more than $5 \%$ of patients (24.8\%). In most of these cases, oral aripiprazole had been discontinued earlier than recommended $(<2$ weeks of the recommended concomitant treatment after first injection). Altogether, 52 TRAEs (39.1\%) improved during the treatment period. Extrapyramidal symptoms and weight disturbances that were reported as treatment-related were rare (Table 4). No TRAEs were recorded related to sexual dysfunction, such as hyperprolactinemia. No patients died during the study.

\section{Discussion}

The therapeutic effect of AOM treatment in schizophrenia was shown in previous RCTs, which were initiated to determine its efficacy [20, 21, 25]. Furthermore, the effect of oral aripiprazole was studied in short-term as well

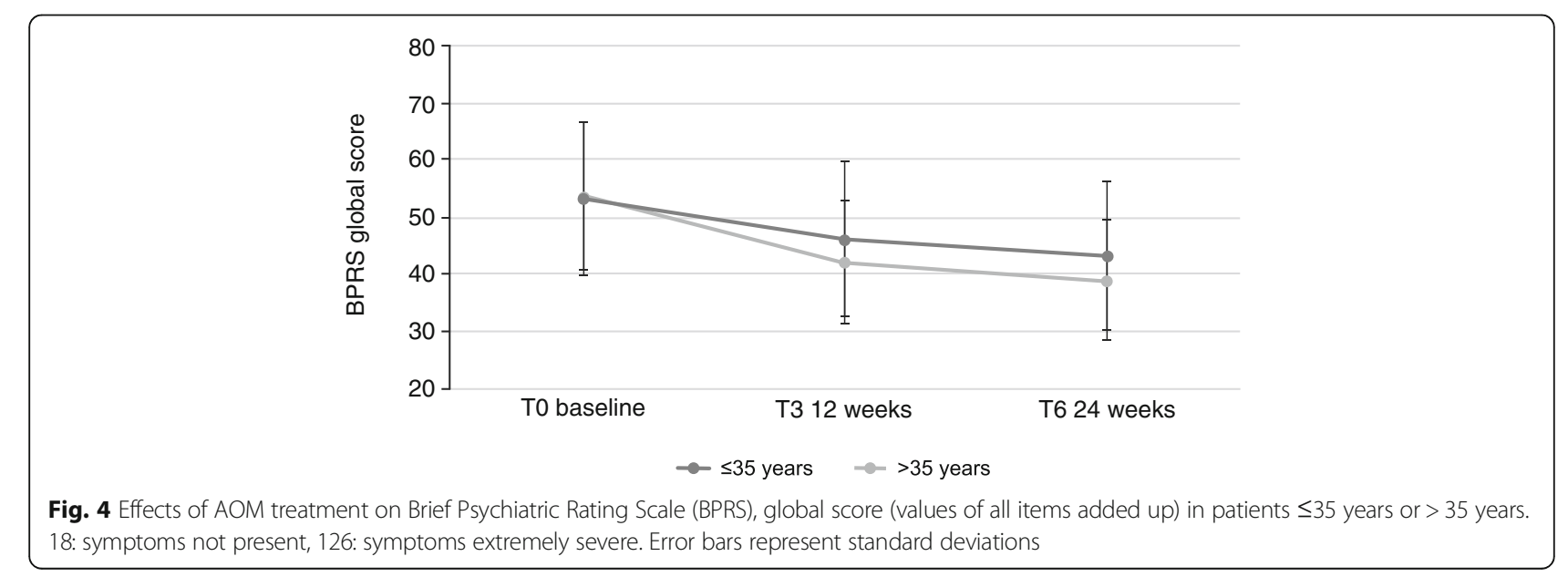


Table 3 Differences in BPRS subscores, stratified by patient age

\begin{tabular}{lll}
\hline BPRS subscore & $\leq 35$ years T6-T0 $(\mathrm{SD} ;[95 \% \mathrm{CI})$ & $>35$ years T6-T0 (SD; [95\% CI]) \\
\hline Anxiety/depression & $-1.19(1.21 ;[-1.46 ;-0.93])$ & $-0.87(1.20 ;[-1.06 ;-0.67])$ \\
Anergia & $-0.83(1.08 ;[-1.06 ;-0.59])$ & $-0.57(0.83 ;[-0.71 ;-0.43])$ \\
Thought disorders & $-0.92(1.08 ;[-1.15 ;-0.68])$ & $-0.54(0.86 ;[-0.69 ;-0.40])$ \\
Activation & $-0.97(1.19 ;[-1.23 ;-0.71])$ & $-0.74(1.13 ;[-0.92 ;-0.55])$ \\
Hostility/mistrust & $-0.85(1.23 ;[-1.12 ;-0.58])$ & $-0.57(0.98 ;[-0.74 ;-0.41])$ \\
\hline
\end{tabular}

All differences were significant $(p<0.001)$

BPRS Brief Psychiatric Rating Scale

as long-term therapy for bipolar disorder [26]. AOM has also been approved by the FDA for the treatment of bipolar disorder [27] and a real-world study has been conducted on AOM use for both bipolar disorder and schizophrenia [28]. However, in Europe, AOM is only approved for schizophrenia treatment. Here, we report prospectively collected real-world data in a relatively large cohort in Germany. This prospective non-interventional study was conducted to support and amplify the effectiveness of AOM treatment in a naturalistic setting of usual-care patients being treated with oral aripiprazole before enrollment in the study.

The main findings were that during the 6-month observation period, patients experienced significant improvements in psychopathology and in severity of illness scale scores. The global BPRS values were significantly better already after 12 weeks $(p<0.001)$, with further significant improvement after 24 weeks $(p<0.001)$. This effect was numerically more prominent in younger patients $\leq 35$ years.

In line with the results from the BPRS, CGI-S and CGI-I values also improved significantly during the study period. There were fewer patients with high scores and more patients with low scores at the end of the study, with significant differences between start and end of the study. This finding is in agreement with the improvements seen in the CGI-S values of patients in a previous study [25]. The improvements were significantly stronger in younger patients $\leq 35$ years.

The results of numerically or statistically significant greater improvements in the younger age group further highlight the importance of early and consequent therapeutic intervention, which may help protect patients from the potential deteriorating effects of experiencing repeated psychotic episodes [29-31].

Some patients worsened during the study. Altogether, 29 patients (12\%) achieved worse ratings on the BPRS, and 13 patients $(5.4 \%)$ were considered worse on the CGI-S scale. In most cases, the deterioration was minimal and may have been the result of normal variation of the patient's status. Seven patients worsened by 10 points on the BPRS and four patients worsened by two points on the CGI-S. However, other studies found similar rates of deterioration among their patients. [21] In the registration trial for AOM by Kane et al., 10\% of patients in the active group experienced exacerbation of psychotic symptoms or impending relapse despite receiving ongoing AOM treatment [20]. In the European

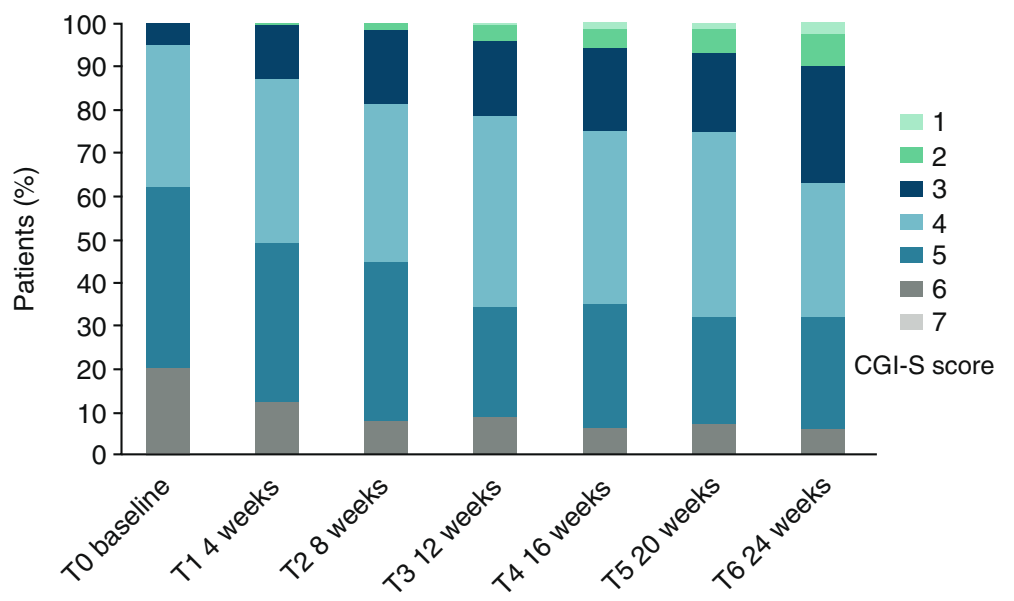

Fig. 5 Clinical Global Impression - Severity (CGI-S), scores between 1 (not at all ill) and 7 (among the most extremely ill patients). Percentage of patients with each score is shown 


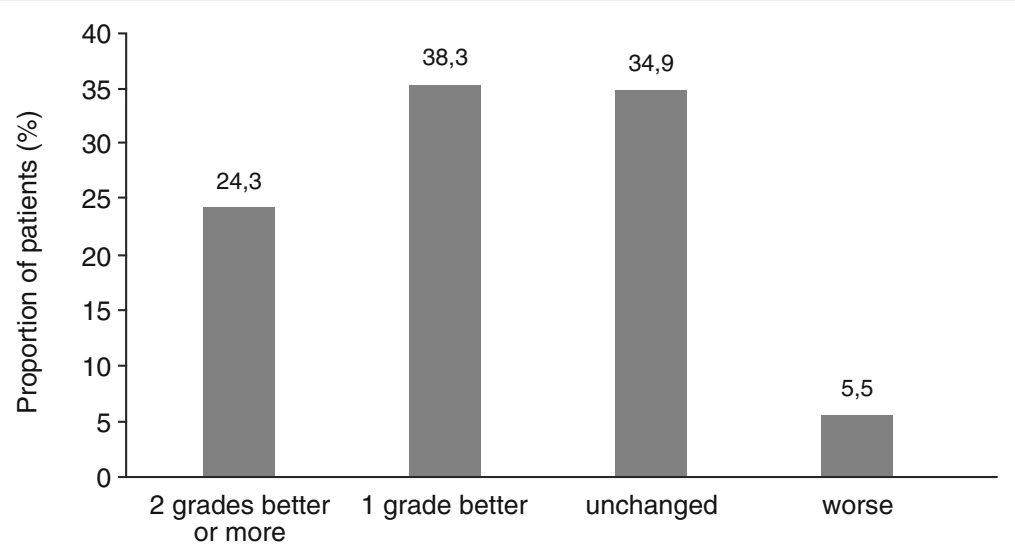

Fig. 6 Percentages of patients with defined changes in the CGI-S score between T0 and T6. Data were missing for 7 patients

registration trial, Kaplan-Meier estimated impending relapse rates at week 26 from randomization were $7.1 \%$ for AOM $400 \mathrm{mg}$ [21]. Finally, the proportion of patients on AOM or oral aripiprazole meeting exacerbation of psychotic symptoms/relapse criteria at the endpoint of a study by Ishigooka et al. was 6.6\% [32]. Reasons for breakthrough psychosis may be psychosocial, comorbidity-related, pharmacokinetic/administration-related, or biological in nature [33], yet the exact reasons for the worsening in the patients in this study are unknown to us.

Among other variables, adherence to psychopharmacological treatment is considerably influenced by the occurrence of side effects of the medication [34]. Particularly

Table 4 Adverse Events (AE), coded according to MedDRA19.0

\begin{tabular}{ll}
\hline Adverse Events, $n$ (\% of patients) & $153(42.2)$ \\
\hline Any AE & $133(39.7)$ \\
TRAE & \\
Specific TRAE occurring in $\geq 5 \%$ of patients & $60(24.8)$ \\
$\quad$ Medication taken at inappropriate time ${ }^{a}$ & $7(2.9)$ \\
TRAEs related to extrapyramidal symptoms & $1(0.4)$ \\
Akathisia & $0(0)$ \\
Dystonia & $1(0.4)$ \\
Extrapyramidal disorder & $0(0)$ \\
Muscle rigidity & $1(0.4)$ \\
Muscle spasms & $2(0.8)$ \\
Tremor & $1(0.4)$ \\
Parkinsonism & $1(0.4)$ \\
Parkinson gait & $1(0.4)$ \\
TRAEs related to weight change & $1(0.4)$ \\
Weight increased & $0(0)$ \\
Weight decreased & \\
\hline Treatment related adverse events (TRAE) were defined as events probably or \\
possibly caused by the medication as estimated by the treating clinician \\
aln most cases, oral aripiprazole was discontinued at an earlier time \\
than recommended
\end{tabular}

side effects, such as weight gain, experiencing extrapyramidal symptoms, or side effects related to hyperprolactinemia, such as sexual dysfunction, are common causes for stopping medication [35]. In our study, these side effects were rare. According to our medication monitoring, 84\% of the patients were fully adherent to medication, which supports the notion, that patients prefer an effective and well tolerable psychopharmacological treatment.

Interestingly, only few TRAEs were recorded during the study, which were not different in the age subgroup analyses. TRAEs related to extrapyramidal symptoms (2.9\%), weight increase $(0.4 \%)$ or hyperprolactinemia (0\%) were very rare. Extrapyramidal symptoms were only found in patients $>35$ years who were diagnosed with schizophrenia $>5$ years ago.

Although LAIs can lead to improved adherence rates and potentially to improved long-term outcomes, there has been some debate about the effectiveness of LAIs in the long-term treatment of schizophrenia: the advantages of LAIs in comparison to continuous oral medication have been repeatedly questioned. However, comparison of different study types, such as RCTs [36], mirror image studies [12], and retrospective as well as prospective cohort studies [14] revealed that differences regarding the effectiveness of LAIs are likely dependent on how representative and severely ill the studies sample is $[37,38]$.

Studies suggested that therapeutic alliance is one of the most important factors affecting adherence [34]. Moreover, studies of collaborative care, which can increase the alliance between the treatment team and the patient, and which respects the patients and their autonomy, have led to significant improvements in adherence rates. We believe that focusing on therapeutic alliance via provision of concurrent psychosocial interventions is important to optimize outcomes, even while using long-acting injectable antipsychotics [39, 40].

In contrast to RCTs with a highly selected study population, both naturalistic study types in general showed 
better effectiveness. In our study, we could broaden and support findings from RCTs with AOM and show that comparable efficacy results could be obtained.

The observed statistically and clinically relevant improvements in psychopathology and severity of illness ratings are particularly noteworthy, as patients had already received an average of 9.7 months of oral aripiprazole, and $87.9 \%$ were deemed by the clinicians as "clinically stable" and for an average of 5.9 months. Thus, the additional improvements in a real-world sample are at least in some relevant part attributable to a change in formulation of the antipsychotic and the related more consistent and reliable delivery of the antipsychotic medication [13]. The fact that $89.3 \%$ of the patients decided to continue with AOM after the 6-month observational period further underscores the acceptability of this treatment option.

These findings are in line with the study comparing aripiprazole and paliperidone LAI by Naber et al. [25] where the CGI-S scores also improved continuously during treatment with AOM. In the RCT studies of AOM compared to placebo by $[20,32]$ the PANSS score remained stable for 52 weeks, and in the noninferiority study compared to oral aripiprazole by Fleischhacker et al., [41] the PANSS score was stable for 38 weeks after switching to treatment with AOM. Similarly, a study comparing risperidone LAI with oral antipsychotics for 1 year found that frequent medication switches led to less favorable outcomes [42], suggesting that antipsychotic medication stability might be an important factor for improved or stable outcomes in patients with schizophrenia.

Similar positive results for AOM treatment as in our study were found in another naturalistic study that used the Positive and Negative Syndrome Scale (PANSS) and CGI scales as endpoints [43]. In that study, highly significant improvements were found as early as 4 weeks after study start.

Finally, in the past, observational studies on the use of aripiprazole in patients with bipolar disorder also confirmed the efficacy results of RCTs [44], showing that aripiprazole was effective both in controlled experimental settings and in real world clinical practice settings.

Due to its naturalistic, non-interventional design, this study has several limitations. Importantly, there is a risk of a selection bias (e.g., patients were willing to take LAI medication), and of an expectation bias (knowledge of being on the LAI formulation of aripiprazole and of being in a study), there are no reference points other than baseline (patient's condition at T0), and due to a lack of any randomization there are possible confounding factors, which cannot be identified or excluded. The dose of AOM varied during the study period, which can also be a confounding factor. Finally, all patients had already received and tolerated oral aripiprazole. Nevertheless, the initiation with oral aripiprazole before starting AOM is according to the package insert and clinical guidelines, and inclusion of patients who were selected under usual care conditions as being clinically eligible for AOM treatment increases the external validity and generalizability of the findings.

In general, most often, observational studies produce results that are similar to those of RCTs [45-47], although in some cases the magnitude of an observed effect is different [48-50]. If the observational studies are well-designed, their results do not seem to systematically overestimate treatment effects from RCTs [51, 52]. Therefore, observational studies are an important complement to RCTs [53] in order to evaluate the feasibility of a given treatment and generalizability of the findings to less restricted patient populations, both regarding the magnitude of efficacy and of safety signals.

\section{Conclusions}

Taken together, our results support previous results of the efficacy, tolerability and acceptability of AOM under routine clinical practice conditions. Outpatients who already respond to oral aripiprazole can further benefit from treatment with AOM, which proved to be effective under routine clinical conditions in a "real-life" sample of patients with schizophrenia. TRAEs were rare, a finding that is particularly important for patients who often undergo long-term antipsychotic treatment and who frequently have psychiatric and medical comorbidities and receive comedications, each of which are restricted in RCTs. The positive therapeutic effect was pronounced in younger patients, which underlines the need for early and continuous treatment.

\section{Abbreviations}

AE: Adverse event; AOM: Aripiprazole once-monthly; BPRS: Brief psychiatric rating scale; CGI-I: Clinical global impression - improvement; CGI-S: Clinical global impression - severity; ICD: International classification of diseases;

LAl: Long-acting injectable; LOCF: Last observation carried forward; PANSS: Positive and negative syndrome scale; RCT: Randomized controlled trial; SD: Standard deviation; TRAE: Treatment related adverse event

\section{Acknowledgements \\ The authors thank the patients participating in this study, as well as their families and caregivers. We further thank Sandra Höpfert and Anfomed $\mathrm{GmbH}$ for implementation of the study and statistical analysis. We thank Kathrin Lemme (Lundbeck GmbH) for support. We also thank Philipp Bauknecht (Dr. Carl GmbH) for medical writing services on behalf of Lundbeck $\mathrm{GmbH}$.}

\section{Funding}

The study was conducted by Otsuka GmbH, Frankfurt, Germany and Lundbeck $\mathrm{GmbH}$, Hamburg, Germany.

The study was sponsored by Lundbeck GmbH and Otsuka GmbH. Conception and Design was made by Prof. Wiedemann and Dr. Janetzky. All other authors made substantial contributions in interpretation of the data and writing the manuscript. Collection and analysis of data were performed by an independent CRO. 


\section{Availability of data and materials}

The datasets used and/or analysed during the current study are available from the corresponding author on reasonable request.

\section{Authors' contributions}

WJ and KW designed the study and wrote the protocol. DS, WJ, DL, CC and KW managed the literature searches and analyses. EB undertook the statistical analysis, and DS wrote the first draft of the manuscript. All authors contributed to and have approved the final manuscript.

\section{Ethics approval and consent to participate}

This study was approved by the Freiburg ethics commission international (Approval number: 014/1336). All patients gave written informed consent. Planning, conduct and evaluation of the NIS was based on legal requirements of the German Medical Products Act (Gesetz über den Verkehr mit Arzneimitteln, §4 (23), sentence 3), the relevant recommendations of the Federal Institute for Drugs and Medical Devices (BfArM) and the Paul-Ehrlich Institute (Empfehlungen des Bundesinstituts für Arzneimittel und Medizinprodukte und des Paul-EhrlichInstituts zur Planung, Durchführung und Auswertung von Anwendungsbeobachtungen 2010) as well as the guidelines of the FSA code (Freiwillige Selbstkontrolle für die Arzneimittelindustrie e. V. 2015),

\section{Consent for publication}

Not applicable.

\section{Competing interests}

DS received honoraria for lectures from Janssen $G \mathrm{mbH}$, Lundbeck GmbH and Otsuka Pharma GmbH, WJ is an employee of Lundbeck GmbH, DL and EB reported no conflicts of interest, CC has been a consultant and/or advisor to or has received honoraria from: Alkermes, Allergan, Gerson Lehrman Group, IntraCellular Therapies, Janssen/J\&, LB Pharma, Lundbeck, Medavante, Medscape, Neurocrine, Otsuka, Pfizer, ROVI, Sunovion, Takeda, and Teva. He has provided expert testimony for Bristol-Myers Squibb, Janssen, and Otsuka. He served on a Data Safety Monitoring Board for Lundbeck, Pfizer, Roche, and ROVI. He received royalties from UpToDate and grant support from Janssen, Neurocrine and Takeda. He is also a shareholder of LB Pharma, KW has been a consultant and received honoraria for lectures from Janssen $\mathrm{GmbH}$, Lundbeck $\mathrm{GmbH}$ and Otsuka Pharma GmbH.

\section{Publisher's Note}

Springer Nature remains neutral with regard to jurisdictional claims in published maps and institutional affiliations.

\begin{abstract}
Author details
${ }^{1}$ Klinik für Psychiatrie und Psychotherapie, Zentrum für Psychosoziale Medizin, Universitätsklinikum Hamburg-Eppendorf, Martinistrasse 52, 20246 Hamburg, Germany. ${ }^{2}$ Lundbeck GmbH, Ericusspitze 2, 20457 Hamburg, Germany. ${ }^{3}$ ANFOMED GmbH, Röttenbacher Str. 17, 91096 Möhrendorf, Germany. ${ }^{4}$ The Zucker Hillside Hospital, Department of Psychiatry, Northwel Health, 75-59 263rd St, Glen Oaks, NY 11004, USA. ${ }^{5}$ Hofstra Northwell School of Medicine, Department of Psychiatry and Molecular Medicine, 500 Hofstra Blvd, Hempstead, NY 11549, USA. ${ }^{6}$ Charité Universitätsmedizin, Department of Child and Adolescent Psychiatry, Augustenburger Platz 1 (Mittelallee 5A), 13353 Berlin, Germany.
\end{abstract}

Received: 19 July 2018 Accepted: 30 October 2018

Published online: 14 November 2018

\section{References}

1. Mitsonis C, Voussoura E, Dimopoulos N, Psarra V, Kararizou E, Latzouraki E, et al. Factors associated with caregiver psychological distress in chronic schizophrenia. Soc Psychiatry Psychiatr Epidemiol. 2012;47:331-7. https://doi. org/10.1007/s00127-010-0325-9.

2. Kahn RS, Sommer IE, Murray RM, Meyer-Lindenberg A, Weinberger DR, Cannon TD, et al. Schizophrenia. Nat Rev Dis Primers. 2015;1:15067. https:// doi.org/10.1038/nrdp.2015.67.

3. Lindenmayer J-P, Liu-Seifert H, Kulkarni PM, Kinon BJ, Stauffer V, Edwards SE, et al. Medication nonadherence and treatment outcome in patients with schizophrenia or schizoaffective disorder with suboptimal prior response. J Clin Psychiatry. 2009;70:990-6. https://doi.org/10.4088/JCP.08m04221.
4. Kane JM, Kishimoto T, Correll CU. Non-adherence to medication in patients with psychotic disorders: epidemiology, contributing factors and management strategies. World Psychiatry. 2013;12:216-26. https://doi.org/10.1002/wps.20060.

5. Szkultecka-Dębek M, Miernik K, Stelmachowski J, Jakovljević M, Jukić V, Aadamsoo K, et al. Schizophrenia causes significant burden to patients' and caregivers' lives. Psychiatr Danub. 2016;28:104-10.

6. Suzuki T, Uchida H, Takeuchi H, Tsuboi T, Hirano J, Mimura M. A review on schizophrenia and relapse--a quest for user-friendly psychopharmacotherapy. Hum Psychopharmacol. 2014;29:414-26. https://doi.org/10.1002/hup.2421.

7. Perkins DO. Predictors of noncompliance in patients with schizophrenia. J Clin Psychiatry. 2002;63:1121-8.

8. Lacro JP, Dunn LB, Dolder CR, Leckband SG, Jeste DV. Prevalence of and risk factors for medication nonadherence in patients with schizophrenia: a comprehensive review of recent literature. J Clin Psychiatry. 2002;63:892-909.

9. Carbon M, Correll CU. Clinical predictors of therapeutic response to antipsychotics in schizophrenia. Dialogues Clin Neurosci. 2014;16:505-24.

10. Weiden PJ, Kozma C, Grogg A, Locklear J. Partial compliance and risk of rehospitalization among California Medicaid patients with schizophrenia. Psychiatr Serv. 2004;55:886-91. https://doi.org/10.1176/appi.ps.55.8.886.

11. De Hert M, Sermon J, Geerts P, Vansteelandt K, Peuskens J, Detraux J. The use of continuous treatment versus placebo or intermittent treatment strategies in stabilized patients with schizophrenia: a systematic review and meta-analysis of randomized controlled trials with first- and secondgeneration antipsychotics. CNS Drugs. 2015;29:637-58. https://doi.org/10. 1007/s40263-015-0269-4.

12. Kishimoto T, Nitta M, Borenstein M, Kane JM, Correll CU. Long-acting injectable versus oral antipsychotics in schizophrenia: a systematic review and meta-analysis of mirror-image studies. J Clin Psychiatry. 2013;74:957-65. https://doi.org/10.4088/JCP.13r08440.

13. Correll CU, Citrome L, Haddad PM, Lauriello J, Olfson M, Calloway SM, et al. The use of long-acting injectable antipsychotics in schizophrenia: evaluating the evidence. J Clin Psychiatry. 2016;77(suppl 3):1-24. https://doi.org/10. 4088/JCP.15032su1.

14. Kishimoto T, Hagi K, Nitta M, Leucht S, Olfson M, Kane JM, et al. Effectiveness of long-acting injectable vs Oral antipsychotics in patients with schizophrenia: a meta-analysis of prospective and retrospective cohort studies. Schizophr Bull. 2017:44:603-19. https://doi.org/10.1093/schbul/sbx090.

15. Burris KD, Molski TF, Xu C, Ryan E, Tottori K, Kikuchi T, et al. Aripiprazole, a novel antipsychotic, is a high-affinity partial agonist at human dopamine D2 receptors. J Pharmacol Exp Ther. 2002;302:381-9. https://doi.org/10.1124/ jpet.102.033175

16. Shapiro DA, Renock S, Arrington E, Chiodo LA, Liu L-X, Sibley DR, et al. Aripiprazole, a novel atypical antipsychotic drug with a unique and robust pharmacology. Neuropsychopharmacology. 2003;28:1400-11. https://doi. org/10.1038/sj.npp.1300203.

17. de Boer MK, Castelein S, Wiersma D, Schoevers RA, Knegtering H. The facts about sexual (Dys)function in schizophrenia: an overview of clinically relevant findings. Schizophr Bull. 2015;41:674-86. https://doi.org/ 10.1093/schbul/sbv001.

18. Jordan S, Koprivica V, Chen R, Tottori K, Kikuchi T, Altar CA. The antipsychotic aripiprazole is a potent, partial agonist at the human 5-HT1A receptor. Eur J Pharmacol. 2002;441:137-40.

19. Stark AD, Jordan S, Allers KA, Bertekap RL, Chen R, Mistry Kannan T, et al. Interaction of the novel antipsychotic aripiprazole with 5-HT1A and 5-HT 2A receptors: functional receptor-binding and in vivo electrophysiological studies. Psychopharmacology. 2007;190:373-82. https://doi.org/10.1007/ s00213-006-0621-y.

20. Kane JM, Sanchez R, Perry PP, Jin N, Johnson BR, Forbes RA, et al. Aripiprazole intramuscular depot as maintenance treatment in patients with schizophrenia: a 52-week, multicenter, randomized, double-blind, placebocontrolled study. J Clin Psychiatry. 2012;73:617-24. https://doi.org/10.4088/ JCP. $11 \mathrm{~m} 07530$.

21. Fleischhacker WW, Sanchez R, Perry PP, Jin N, Peters-Strickland T, Johnson BR, et al. Aripiprazole once-monthly for treatment of schizophrenia: double-blind, randomised, non-inferiority study. Br J Psychiatry. 2014;205:135-44. https://doi. org/10.1192/bjp.bp.113.134213.

22. Potkin SG, Preda A. Aripiprazole once-monthly long-acting injectable for the treatment of schizophrenia. Expert Opin Pharmacother. 2016;17:395-407. https://doi.org/10.1517/14656566.2015.1114100.

23. Overall JE, Gorham DR. The brief psychiatric rating scale. Psychol Rep. 1962; 10:799-812 
24. Guy W. ECDEU assessment manual for psychopharmacology - revised (DHEW Publ no ADM 76-338). Rockville: U.S. Department of Health, Education, and Welfare, Public Health Service, Alcohol, Drug Abuse, and Mental Health Administration, NIMH Psychopharmacology Research Branch, Division of Extramural Research Programs; 1976.

25. Naber D, Hansen K, Forray C, Baker RA, Sapin C, Beillat M, et al. Qualify: a randomized head-to-head study of aripiprazole once-monthly and paliperidone palmitate in the treatment of schizophrenia. Schizophr Res. 2015;168:498-504. https://doi.org/10.1016/j.schres.2015.07.007.

26. McKeage K. Aripiprazole: a review of its use in the treatment of manic episodes in adolescents with bipolar I disorder. CNS Drugs. 2014;28:171-83. https://doi.org/10.1007/s40263-013-0134-2.

27. Calabrese JR, Sanchez R, Jin N, Amatniek J, Cox K, Johnson B, et al. The safety and tolerability of aripiprazole once-monthly as maintenance treatment for bipolar I disorder: a double-blind, placebo-controlled, randomized withdrawal study. J Affect Disord. 2018;241:425-32. https://doi. org/10.1016/j.jad.2018.06.043.

28. Yan T, Greene M, Chang E, Hartry A, Touya M, Broder MS. Medication adherence and discontinuation of aripiprazole once-monthly $400 \mathrm{mg}$ (AOM 400) versus Oral antipsychotics in patients with schizophrenia or bipolar I disorder: a real-world study using US claims data. Adv Ther. 2018. https:// doi.org/10.1007/s12325-018-0785-y.

29. Emsley R, Chiliza B, Asmal L. The evidence for illness progression after relapse in schizophrenia. Schizophr Res. 2013;148:117-21. https://doi.org/10. 1016/j.schres.2013.05.016.

30. Stahl SM. Long-acting injectable antipsychotics: shall the last be first? CNS Spectr. 2014;19:3-5. https://doi.org/10.1017/S1092852913001016.

31. Tiihonen J, Haukka J, Taylor M, Haddad PM, Patel MX, Korhonen P. A nationwide cohort study of oral and depot antipsychotics after first hospitalization for schizophrenia. Am J Psychiatry. 2011;168:603-9. https:// doi.org/10.1176/appi.ajp.2011.10081224.

32. Ishigooka J, Nakamura J, Fujii Y, Iwata N, Kishimoto T, lyo M, et al. Efficacy and safety of aripiprazole once-monthly in Asian patients with schizophrenia: a multicenter, randomized, double-blind, non-inferiority study versus oral aripiprazole. Schizophr Res. 2015;161:421-8. https://doi.org/10. 1016/.s.schres.2014.12.013.

33. Correll CU, Kern Sliwa J, Najarian DM, Saklad SR. Practical considerations for managing breakthrough psychosis and symptomatic worsening in patients with schizophrenia on long-acting injectable antipsychotics. CNS Spectr. 2018. In press.

34. Velligan DI, Sajatovic M, Hatch A, Kramata P, Docherty JP. Why do psychiatric patients stop antipsychotic medication? A systematic review of reasons for nonadherence to medication in patients with serious mental illness. Patient Prefer Adherence. 2017;11:449-68. https://doi.org/10.2147/PPA.S124658.

35. Velligan DI, Weiden PJ, Sajatovic M, Scott J, Carpenter D, Ross R, et al. The expert consensus guideline series: adherence problems in patients with serious and persistent mental illness. J Clin Psychiatry. 2009;70(Suppl 4):1-46 quiz 47.

36. Kishimoto T, Robenzadeh A, Leucht C, Leucht S, Watanabe K, Mimura M, et al. Long-acting injectable vs oral antipsychotics for relapse prevention in schizophrenia: a meta-analysis of randomized trials. Schizophr Bull. 2014;40: 192-213. https://doi.org/10.1093/schbul/sbs150.

37. Kirson NY, Weiden PJ, Yermakov S, Huang W, Samuelson T, Offord SJ, et al. Efficacy and effectiveness of depot versus oral antipsychotics in schizophrenia: synthesizing results across different research designs. J Clin Psychiatry. 2013;74:568-75. https://doi.org/10.4088/JCP.12r08167.

38. Kane JM, Kishimoto T, Correll CU. Assessing the comparative effectiveness of long-acting injectable vs. oral antipsychotic medications in the prevention of relapse provides a case study in comparative effectiveness research in psychiatry. J Clin Epidemiol. 2013;66(8 Suppl):S37-41. https://doi.org/10. 1016/j.jclinepi.2013.01.012.

39. Schöttle D, Schimmelmann BG, Ruppelt F, Bussopulos A, Frieling M, Nika E, et al. Effectiveness of integrated care including therapeutic assertive community treatment in severe schizophrenia-spectrum and bipolar I disorders: four-year follow-up of the ACCESS II study. PLoS One. 2018;13 e0192929. https://doi.org/10.1371/journal.pone.0192929.

40. Schöttle D, Schimmelmann BG, Karow A, Ruppelt F, Sauerbier A-L, Bussopulos A, et al. Effectiveness of integrated care including therapeutic assertive community treatment in severe schizophrenia spectrum and bipolar I disorders: the 24-month follow-up ACCESS I| study. J Clin Psychiatry. 2014;75:1371-9. https://doi.org/10.4088/JCP.13m08817.
41. Fleischhacker WW, Baker RA, Eramo A, Sanchez R, Tsai L-F, Peters-Strickland T, et al. Effects of aripiprazole once-monthly on domains of personal and social performance: results from 2 multicenter, randomized, double-blind studies. Schizophr Res. 2014;159:415-20. https://doi.org/10.1016/.schres.2014.09.019.

42. Schreiner A, Svensson A, Wapenaar R, Cherubin P, Princet P, Serazetdinova L, et al. Long-acting injectable risperidone and oral antipsychotics in patients with schizophrenia: results from a prospective, 1-year, non-interventional study (InORS). World J Biol Psychiatry. 2014;15:534-45. https://doi.org/10.3109/ 15622975.2014.902990.

43. Peters-Strickland T, Zhao C, Perry PP, Eramo A, Salzman PM, McQuade RD, et al. Effects of aripiprazole once-monthly on symptoms of schizophrenia in patients switched from oral antipsychotics. CNS Spectr. 2016;21:1-6. https://doi.org/10.1017/S1092852916000365.

44. Meduri M, Gregoraci G, Baglivo V, Balestrieri M, Isola M, Brambilla P. A metaanalysis of efficacy and safety of aripiprazole in adult and pediatric bipolar disorder in randomized controlled trials and observational studies. J Affect Disord. 2016;191:187-208. https://doi.org/10.1016/j.jad.2015.11.033.

45. Atar D, Ong S, Lansberg PJ. Expanding the evidence base: comparing randomized controlled trials and observational studies of statins. Am J Ther. 2015;22:e141-50. https://doi.org/10.1097/MJT.0b013e318245ce94.

46. Rouch L, Cestac P, Hanon O, Cool C, Helmer C, Bouhanick B, et al. Antihypertensive drugs, prevention of cognitive decline and dementia: a systematic review of observational studies, randomized controlled trials and meta-analyses, with discussion of potential mechanisms. CNS Drugs. 2015; 29:113-30. https://doi.org/10.1007/s40263-015-0230-6.

47. Golder S, Loke YK, Bland M. Meta-analyses of adverse effects data derived from randomised controlled trials as compared to observational studies: methodological overview. PLoS Med. 2011;8:e1001026. https://doi.org/10. 1371/journal.pmed.1001026.

48. Ahrén B, Mathieu C, Bader G, Schweizer A, Foley JE. Efficacy of vildagliptin versus sulfonylureas as add-on therapy to metformin: comparison of results from randomised controlled and observational studies. Diabetologia. 2014; 57:1304-7. https://doi.org/10.1007/s00125-014-3222-z.

49. Naudet F, Maria AS, Falissard B. Antidepressant response in major depressive disorder: a meta-regression comparison of randomized controlled trials and observational studies. PLoS One. 2011;6:e20811. https://doi.org/10.1371/ journal.pone.0020811.

50. Conaty S, Watson L, Dinnes J, Waugh N. The effectiveness of pneumococcal polysaccharide vaccines in adults: a systematic review of observational studies and comparison with results from randomised controlled trials. Vaccine. 2004;22:3214-24. https://doi.org/10.1016/j.vaccine.2003.08.050.

51. Concato J, Shah N, Horwitz RI. Randomized, controlled trials, observational studies, and the hierarchy of research designs. N Engl J Med. 2000;342: 1887-92. https://doi.org/10.1056/NEJM200006223422507.

52. Benson K, Hartz AJ. A comparison of observational studies and randomized, controlled trials. N Engl J Med. 2000;342:1878-86. https://doi.org/10.1056/ NEJM200006223422506.

53. Yang W, Zilov A, Soewondo P, Bech OM, Sekkal F, Home PD. Observational studies: going beyond the boundaries of randomized controlled trials. Diabetes Res Clin Pract. 2010;88(Suppl 1):S3-9. https://doi.org/10.1016/ S0168-8227(10)70002-4.

\section{Ready to submit your research? Choose BMC and benefit from:}

- fast, convenient online submission

- thorough peer review by experienced researchers in your field

- rapid publication on acceptance

- support for research data, including large and complex data types

- gold Open Access which fosters wider collaboration and increased citations

- maximum visibility for your research: over $100 \mathrm{M}$ website views per year

At BMC, research is always in progress.

Learn more biomedcentral.com/submissions 